\title{
Coronary Artery Fistulae: Indications For Treatment and Technical Considerations
}

\author{
Ashish H Shah, MD, MD-Research, MRCP, Andrew Leventhal, MD, PhD, Mark Osten, MD, FRCPC, \\ Lee Benson, MD, FRCPC, Eric Horlick, MDCM, FRCPC ${ }^{*}$
}

Peter Munk Cardiac Centre and Toronto Congenital Cardiac Centre for Adults, Toronto General Hospital, University Health Network, Toronto, ON, Canada

\begin{abstract}
Coronary artery fistulae is an uncommon cardiac condition. Trans catheter closure of fistula remains the treatment of choice. Due to the condition being very uncommon, individual experience remains limited. In the present article, we have described various aspects of coronary artery fistula and their management.
\end{abstract}

\section{Key Words}

\section{Coronary artery fistula • Transcatheter closure.}

\section{Introduction}

Coronary artery fistulas (CAFs) are an uncommon cardiovascular anomaly characterized by a connection between a coronary artery and an adjacent vessel (coronary arteriovenous fistula) or a cardiac chamber (coronary-cameral fistula) without an intervening capillary network [1]. It is the result of a defect early in the development of the myocardium, prior to compaction, and leads to the persistence of sinusoids, resulting in a coronary-cameral fistula, whereas a defect at a later stage of development results in a CAF.

\section{Incidence}

The true incidence of CAFs is unknown, as the majority of patients remain clinically asymptomatic. Their presence may be suggested by an audible cardiac murmur, or by way of diagnostic imaging with either an echocardiogram or coronary angiography [2].

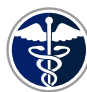

Fax +1 2037853346

E-Mail: jshd@scienceinternational.org

http://structuralheartdisease.org/ (c) 2016 Journal of Structural Heart Disease Published by Science International Corp. ISSN 2326-4004

Accessible online at: http://structuralheartdisease.org/
Coronary arteriovenous fistulae: Indications for treatment and technical considerations

Ashish Shah, Andrew Leventhal, Mark Osten, Lee Benson, Eric Horlick

Toronto Congenital Cardiac Centre for Adults, Peter Munk Cardiac Centre, University Health Network, Toronto, ON, Canada

DOI: http://dx.doi.org/10.12945/j.jshd.2016.013-14

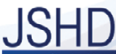

Slideshow. Click on the presentation above to view the presentation online. Please be aware that the presentation has many embedded videos so there is a long load time (127.4 MB). You may download the file at http://dx.doi.org/10.12945/j. jshd.2016.013.14.ppt.01.

The reported incidence is highly variable, ranging from 0.02 to $2.1 \%$, depending on the modality of investigation [3]. In one series, an incidence of $2.1 \%$ was reported, but the majority of patients had left coronary artery to left ventricular micro-fistulae [4]. In a series of 126, 595 patients undergoing diagnostic coronary angiography, the incidence was $0.18 \%$, and the majority were small and the patients were asymptomatic, suggesting that many of the CAFs were co-incidental findings [5]. In children, the incidence has been reported to be $0.06 \%$ from transthoracic echocardiography [6]. Interestingly, a review of literature between

\footnotetext{
* Corresponding Author:

Eric Horlick, MDCM, FRCPC

Peter Munk Cardiac Centre and Toronto Congenital Cardiac Centre for Adults Toronto General Hospital

200 Elizabeth Street, Toronto, ON, M5G 2C4, Canada

Tel.: +1 416340 3835; Fax: +1 416340 3000; E-Mail: Eric.Horlick@uhn.ca
} 
1994 and 2003 found only 236 pediatric and adult patients with CAFs [3]. These lesions can be associated with congenital heart disease, mainly with tetralogy of Fallot or pulmonary atresia $[7,8]$.

\section{Site of Origin and Drainage}

CAFs can arise anywhere in the coronary circulation, but nearly half come from the right coronary artery (RCA) ( 51\%), followed by the left coronary artery and its branches ( 43\%). In a small proportion of patients they originate from both coronaries ( $5 \%)$. In the series reviewed here, nearly $90 \%$ of fistulas drained into the systemic venous circulation; the right ventricle (RV) $(\sim 41 \%)$, right atrium (RA) ( 26\%), pulmonary artery (PA) ( 17\%), coronary sinus (CS) ( 7\%), or superior vena cava (SVC) ( 1\%). CAFs have also been observed to drain into the left atrium (LA) ( 5\%) and left ventricle (LV) ( 3\%) [9]. In the majority of patients, the fistulas enter into their draining chamber/vessel through a single communicating channel, and a minority has multiple entry sites.

\section{Etiologies and Types of CAFs}

In the vast majority of patients, CAFs are present at birth, whereas trauma, myocardial biopsy, chest irradiation, and pacemaker implants can result in an acquired form. Angiographically, the fistulas can be described as proximal or distal, based upon their origin from the coronary artery. Proximal CAFs may be small or large, have single or multiple feeding vessels, originate from one or both coronaries, and are devoid of any nutritive branches. Distal fistulas are usually larger and have high flow [10]. There is no clear definition of what is considered a small, medium, or large fistula by measurement criteria. Generally, small fistulas are clinically silent and do not result in any long-term sequelae, whereas untreated large fistulas are more likely to be associated with myocardial ischemia/infarction, endocarditis, heart failure, rupture, and progressive dilation of the draining chamber/fistula [2].

\section{Physiology of the CAF}

Large CAFs result in (1) shunting of the blood from left to right side (in majority of patients), and (2) have the potential for a 'coronary-steal' phenomena, affecting blood flow to the myocardium supplied by the coronary artery distal to the origin of the fistula. These physiologic changes are influenced by the size of the fistula, pressure difference between the connecting chambers, and co-existence of coronary artery disease. In the only reported animal model (adult foxhounds) of a CAF, the circumflex (LCX) coronary artery was connected to the PA with a vein graft. Calculated mean flow through the fistula was $89 \mathrm{ml} / \mathrm{min}$, resulting in Qp:Qs of 1.1:1. Increasing proximal coronary flow by $211 \%$ and producing a relative steal of $26 \%$ from the coronary artery distal to the fistulas [11]. Doppler wire assessment in a patient with a CAF demonstrated higher systolic and blunted diastolic flow-velocities, which normalized after successful closure [12].

\section{Clinical Presentation \& Differences Based upon Age Group}

Analysis of data published between 1993 and 2004 on patients with CAF, demonstrated that $117 / 128$ (91\%) adult patients were symptomatic vs. 105/133 (79\%) pediatric patients who were asymptomatic. Chest pain and dyspnea were the most common symptoms (71\%), but patients also presented with palpitations $(6.5 \%)$, fatigue (6.5\%), pre-syncope/syncope $(5.6 \%)$, congestive heart failure (3\%), pulmonary hypertension, fistula thrombosis, and rarely rupture or infective endocarditis. An auscultatory finding of a murmur (continuous, systolic or diastolic) was a common physical sign (40\%). The fistulas can grow in size over time and result in symptoms if left untreated. Spontaneous closure and infective endocarditis were more common in the pediatric age group, whereas aneurysmal dilation (14\%), spontaneous rupture (4\%), and co-existing coronary artery disease (19\%) were seen mainly in adult patients [3].

\section{Indication for Treatment and Risk Management}

Our understanding of the natural history of patients with CAFs is significantly limited. According to the American College of Cardiology congenital guidelines, patients with large CAFs should be considered for surgical or transcatheter closure (TCC) irrespective 
of symptoms (Class I, level of evidence C). Additionally, patients with small to moderate fistula, in the presence of documented evidence of myocardial ischemia, arrhythmia, unexplained ventricular dilation or dysfunction, should also be treated with transcatheter or surgical closure [13]. Small fistulas can usually be left untreated and in some cases have been reported to close spontaneously [14]. Alternatively, patients with intermediate sized CAF can be followed with regular surveillance by echocardiogram or CT angiography, and treated if there is evidence of new-onset symptoms, ischemia or progressive dilation. Merely identification of a CAF does not necessitate treatment.

\section{Treatment Options}

The first successful surgical repair of a CAF was performed in 1956, and was the only treatment option until 1983, when TCC became a viable alternative $[15,16]$. Surgical repair remains the treatment of choice for fistulas that are not suitable for TCC as well as in those undergoing surgical repair of other cardiac conditions, for example, congenital cardiac defect repair or coronary artery bypass surgery. Although surgical closure is a relatively low risk procedure, it is associated with inherent risk involved with the surgery. The TCC approach was first used in 1983 using a detachable balloon system [17], and over the years, various closure devices have become readily available, including coils, and vascular plugs. Choice of the device is based upon the size of the fistula, site of device delivery, required catheter size and length. Over the last three decades, TCC has become the preferred treatment option. The risks involved with the procedure include:

- Occluding coronary branches with the device,

- Embolization of clot from the occluded branch,

- Propagation of clot,

- Dissection of coronary artery due to catheter or device manipulation, and

- Arrhythmias

\section{Technical Aspects of the CAF Closure}

TCC of CAFs is a technically challenging procedure, and as the number of procedures performed is small, individual experience remains limited. The decision to treat a CAF should be based upon various factors including: the patient's age, symptoms, fistula size, possibility of progression or rupture, the origin and termination of the fistula, the number of feeding vessels, risk to viable myocardium, risk of residual vessel thrombosis, likelihood of success, and available resources including experience, devices, and personnel. Surgical consultation, specifically for large distal fistulas should almost always be obtained, especially if interventional experience is limited.

Utilization of other imaging modalities in addition to coronary angiography has proven useful for anatomical characterization and can aid strategizing the technical aspects of the procedure. Contrastenhanced $\mathrm{CT}$ is a noninvasive and accurate imaging technique for the detection of CAFs. Multidetector CT has been shown to provide high-resolution anatomic images, and it allows evaluation of aneurysmal dilation or thrombus formation in the vessel. Volume-rendered images acquired from 3D CT data sets provide excellent overviews of the cardiac and vascular anatomy and can help the interventionist or surgeon understand the anatomical complexity.

An operator may choose either an antegrade (via venous circulation) or retrograde (via coronary circulation) approach. Retrograde approaches may be challenging due to anatomy, angulation, kinking, size of the delivery sheath required, and potential risk to coronaries vessels. TCC of proximal CAFs can be performed through a retrograde approach, whereas the same approach for closure of large and especially distal fistulas may be challenging. Delivering a device or coil into the distal part of the coronary circulation, which is likely to be tortuous, requires supportive catheters. Using a larger sized catheter or a catheter in a 'mother-child' format (telescoping) offers good support, but catheter length may be inadequate, especially in those with distal and tortuous lesions, or if the patient is very tall. In such cases antegrade approaches through the venous side would be preferred, although catheter engagement from the venous side can be challenging. Formation of an arterio-venous (AV) loop, where the fistula is wired from the coronary artery and then exteriorized on the venous side (with the help of snare) can be a useful strategy (cross one-way and close the other-way).

In the present article, we will review technical aspects of the TCC of CAFs by outlining various 
procedures we have performed over last few years.

\section{Need for Larger Catheter}

Blood flows at high velocity in large CAFs, and to opacify such vasculature, large volumes of contrast are required. Injecting through either 5 or 6 French (Fr.) sized catheter may not be adequate, and large caliber catheters may be required. As demonstrated here, a large CAF originating from the LCX artery is difficult to opacify with injection through 6 Fr. catheter (Figure 1A). Although an $8 \mathrm{Fr}$. catheter delineates the CAF better (Figure 1B), it failed to demonstrate the distal branches. The vessels were visualized only when distal part of the CAF was occluded with balloon wedge catheter inserted from the venous side over the AV loop (Figure 1C). Presence of a marker catheter in aorta may help with sizing the CAF (Figure 1D), if auto isocenter is not available on the angiographic equipment for calibration.
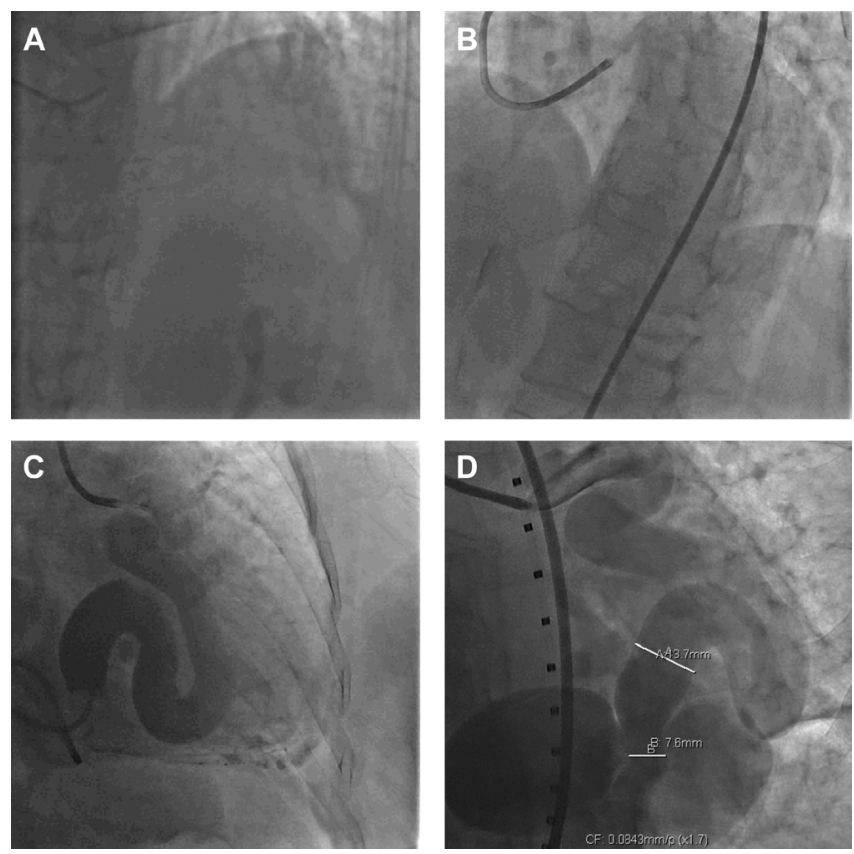

Figure 1. Large CAF - Large catheters. Panel A. View supplementary video at http://dx.doi.org/10.12945/j.jshd.2016.013.14. vid.01. Panel B. View supplementary video at http://dx.doi. org/10.12945/j.jshd.2016.013.14.vid.02. Panel C. View supplementary video at http://dx.doi.org/10.12945/j.jshd.2016.013.14. vid.03. Panel D. View supplementary video at http://dx.doi. org/10.12945/j.jshd.2016.013.14.vid.04.

Journal of Structural Heart Disease, April 2016

\section{Retrograde Approach}

A CAF originating from the proximal part of the coronary artery can be successfully treated through a retrograde approach. A 72-year-old man presented with chest pain and elevated troponin levels. An echocardiogram demonstrated inferior wall hypokinesia, and coronary angiography demonstrated no flow limiting coronary artery disease. There was a medium sized CAF originating from the RCA (Figure $2 A \& B$ ). We treated this fistula using a retrograde approach with an Amplatz left (AL) 0.75-guide catheter and positioned a Renegrade ${ }^{\circledR}$ micro-catheter (Boston Scientific, Marlborough, Massachusetts, USA) over a Pilot $^{\circledR} 50$ guide wire into the fistula. We estimated the fistula diameter to be approximately $4 \mathrm{~mm}$, so first of all we delivered a $5 \mathrm{~mm} \times 15 \mathrm{~cm}$ IDC ${ }^{\circledR}$ platinum, interlock detachable coil (Boston Scientific Inc., USA). As there was residual flow, we delivered two further coils measuring 3 $\mathrm{mm} \times 12 \mathrm{~cm}$ to close the fistula (Figure $2 \mathrm{C} \& \mathrm{D}$ ). Adequate catheter support was very important, and
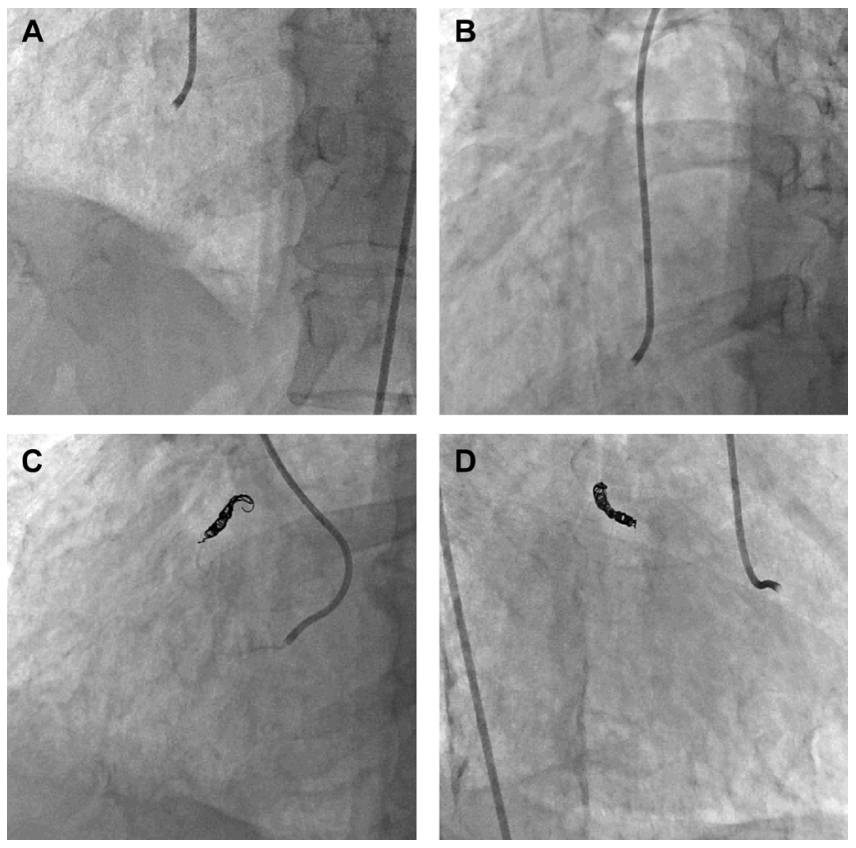

Figure 2. Retrograde approach. Panel A. View supplementary video at http://dx.doi.org/10.12945/j.jshd.2016.013.14. vid.05. Panel B. View supplementary video at http://dx.doi. org/10.12945/j.jshd.2016.013.14.vid.06. Panel C. View supplementary video at http://dx.doi.org/10.12945/j.jshd.2016.013.14. vid.07. Panel D. View supplementary video at http://dx.doi. org/10.12945/j.jshd.2016.013.14.vid.08. 
as one can see here the catheter was pushed out of the RCA despite using an AL guide that are known to be very supportive. We initially chose coils that were nearly $25 \%$ larger in diameter than the CAF, followed by smaller diameter coils to fill up residual gaps until flow was compromised. In the present case, there was some residual sluggish flow at the end of the procedure that was very likely to stop completely over the next few days.

\section{Antegrade Approach}

A 54-year-old man presented with a symptomatic large CAF originating from the LCX draining into SVC. We used a $7 \mathrm{Fr}$. JL4 guide catheter to opacify the CAF. There was gross dilation of the left main and the proximal LCx. The left anterior descending (LAD) artery could not be well visualized due to the high flow state towards the LCx artery (Figure 3A). We used a system consisting of a soft glide exchange wire, a 4
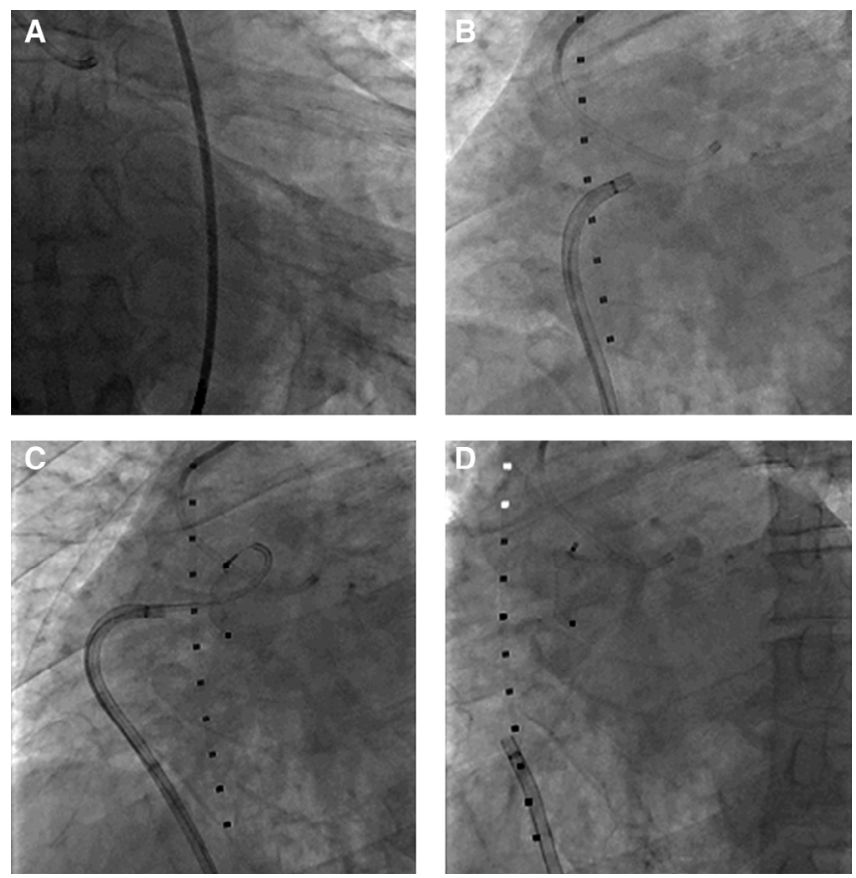

Figure 3. Antegrade closure. Panel A. View supplementary video at http://dx.doi.org/10.12945/j.jshd.2016.013.14.vid.09. Panel B. View supplementary video at http://dx.doi.org/10.12945/j. jshd.2016.013.14.vid.10. Panel C. View supplementary video at http://dx.doi.org/10.12945/j.jshd.2016.013.14.vid.11. Panel D. View supplementary video at http://dx.doi.org/10.12945/j. jshd.2016.013.14.vid.12
Fr. GlideCath ${ }^{\circledast}$, a 6 Fr. multipurpose coronary guide catheter, and the Agilis ${ }^{\circledR}$ sheath (St. Jude Medical Inc., USA) (Figure 3B \& C). This allowed us to make progress with a $6 \mathrm{Fr}$. guide catheter to deliver a 12-mm Amplatz Vascular Plug ${ }^{\circledR}$ II, to successfully occlude the fistula (Figure 3D).

This case demonstrates that if the connection of the fistula on the venous side can be clearly observed, it is possible to perform the TCC from the venous side with help of supportive sheaths and catheters, without need for AV loop formation.

\section{Arterio-Venous Loop Formation}

TCC of large-sized distal CAFs requires closure device and/or coils to be delivered distally, which can be extremely challenging, and on occasion be better performed through an antegrade approach. Cannulation of the draining end of the CAF is challenging, due to difficulty in precise localization and angulation. An AV loop may assist overcoming these challenges. Figure $4 A-D$ demonstrates a patient with a giant CAF originating from the LCX artery, draining into the CS (Figure 4A). The landing site for the device was very distal and we decided to deliver the device through an antegrade approach, over an AV loop. We used an $8 \mathrm{Fr}$. guide catheter to obtain adequate support and initially used 0.035 -inch soft Glidewire ${ }^{\circledR}$ (Terumo Interventional System, Japan), which just looped but did not exit the CS (Figure 4B). We then used a $300-\mathrm{cm}$ exchange length Prowater ${ }^{\oplus}$ guide wire supported by a Finecross ${ }^{\oplus}$ micro-catheter (Terumo Interventional System, Japan) to traverse through CS into the RA, where it was snared and exteriorized via the femoral vein (Figure $4 C \& D$ ). We advanced a $7 \mathrm{Fr}$. balloon wedge catheter through the venous side into the distal part of the fistula (Figure 4E). With the balloon inflated, we obtained much better images of the left coronary system, and could appreciate a distal branch (Figure 4F). Then we delivered the balloon wedge catheter into the left main coronary artery and introduced it into the nose of an $8 \mathrm{Fr}$. guiding catheter (kissing catheter technique) (Figure $4 \mathrm{G})$. This allowed us to exchange a coronary wire for a $260-\mathrm{cm}$ Glidewire ${ }^{\circledR}$ to form an AV loop (Figure 4H). We engaged a $6 \mathrm{Fr}$. $\mathrm{AGA}^{\oplus}$ delivery system, from the venous side into the mid LCX (Figure $4 \mathrm{I} \& \mathrm{~J}$ ). We chose 

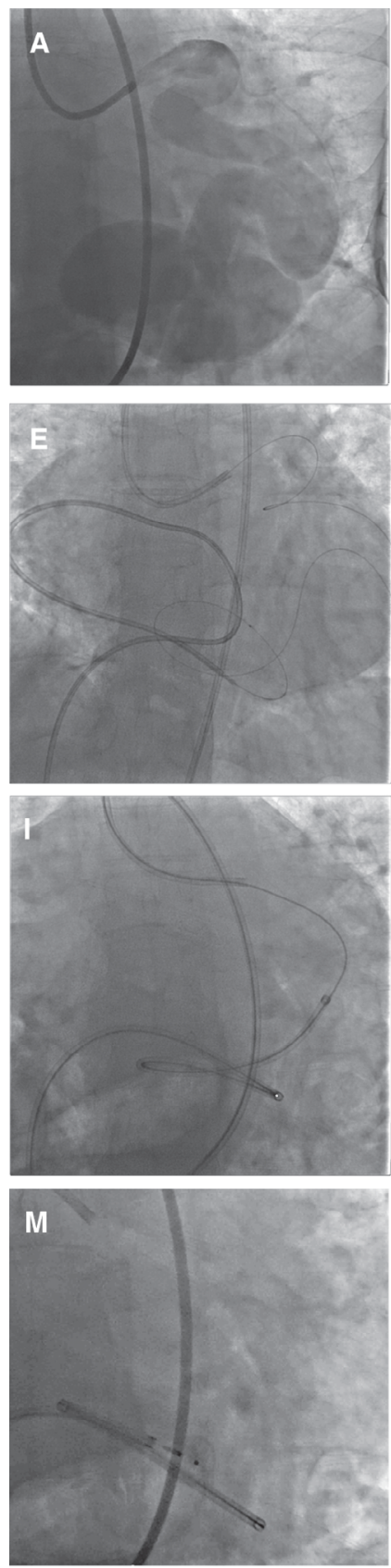
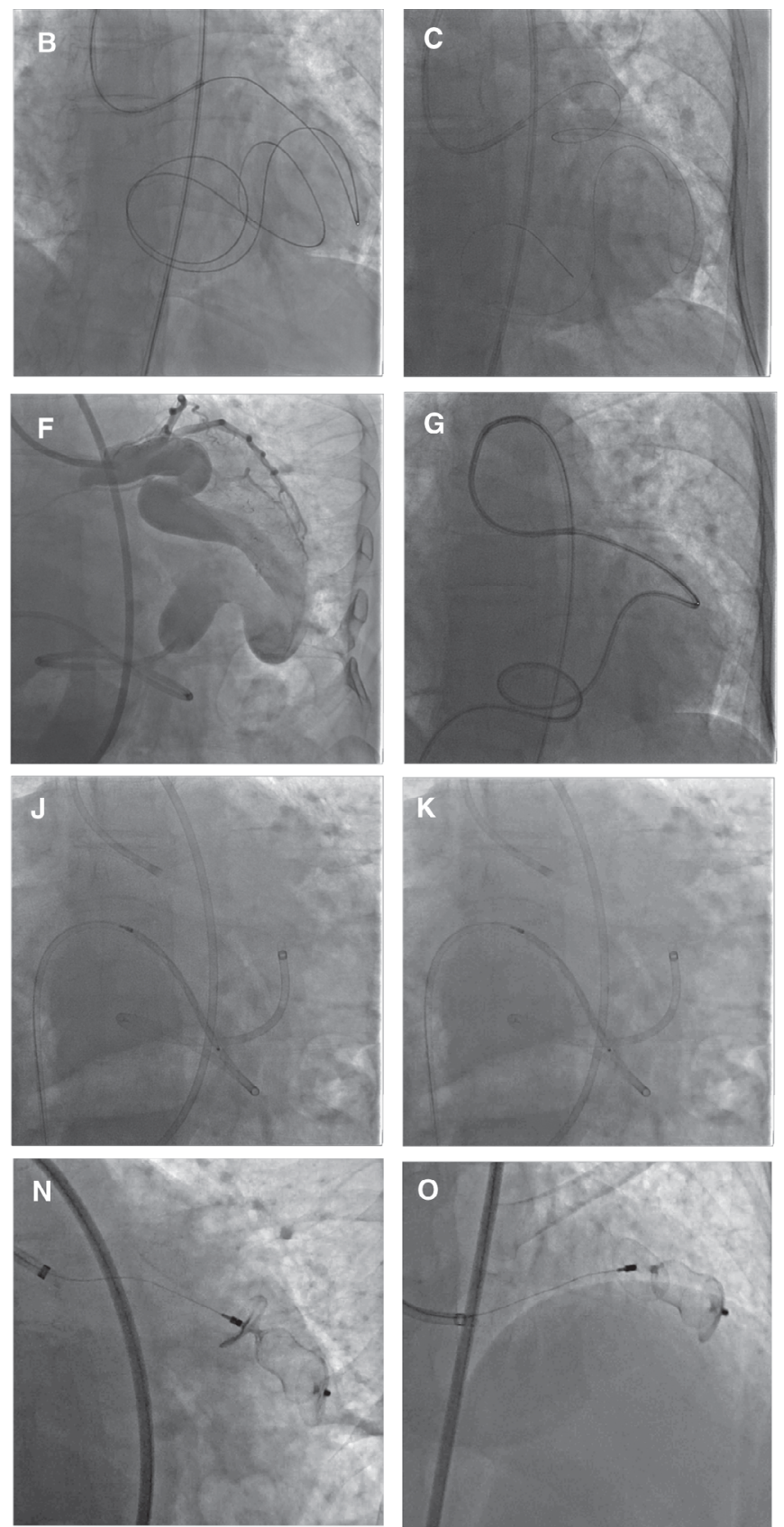
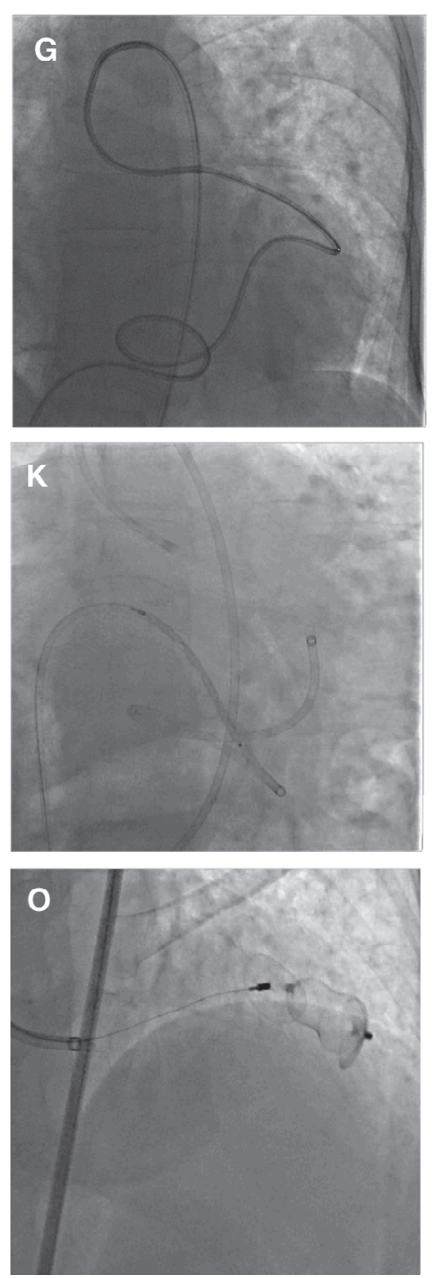
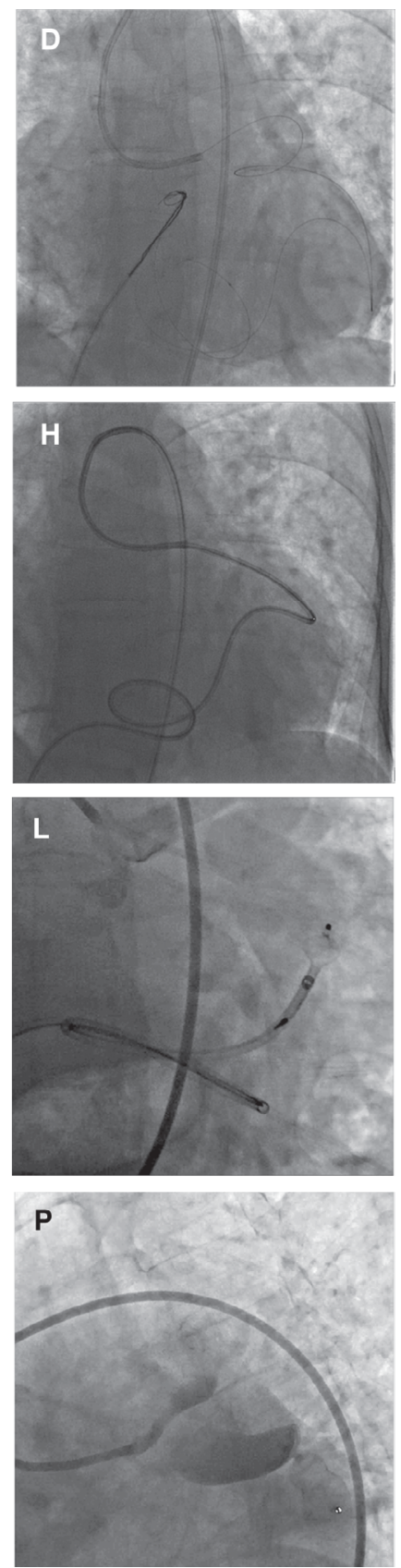

Figure 4. Arterio-venous. Panel A. View supplementary video at http://dx.doi.org/10.12945/j.jshd.2016.013.14.vid.13. Panel B. View supplementary video at http://dx.doi.org/10.12945/j.jshd.2016.013.14.vid.14. Panel C. View supplementary video at http://dx.doi. org/10.12945/j.jshd.2016.013.14.vid.15. Panel D. View supplementary video at http://dx.doi.org/10.12945/j.jshd.2016.013.14.vid.16. PanelE. View supplementary video at http://dx.doi.org/10.12945/j.jshd.2016.013.14.vid.17. Panel F. View supplementary video at http://dx.doi. org/10.12945/j.jshd.2016.013.14.vid.18. Panel G. View supplementary video at http://dx.doi.org/10.12945/j.jshd.2016.013.14.vid.19. Panel H. View supplementary video at http://dx.doi.org/10.12945/j.jshd.2016.013.14.vid.20. Panel I. View supplementary video at http://dx.doi. org/10.12945/j.jshd.2016.013.14.vid.21. Panel J. View supplementary video at http://dx.doi.org/10.12945/j.jshd.2016.013.14.vid.22. Panel K. View supplementary video at http://dx.doi.org/10.12945/j.jshd.2016.013.14.vid.23. Panel L. View supplementary video at http://dx.doi. org/10.12945/j.jshd.2016.013.14.vid.24. Panel M. View supplementary video at http://dx.doi.org/10.12945/j.jshd.2016.013.14.vid.25. Panel N. View supplementary video at http://dx.doi.org/10.12945/j.jshd.2016.013.14.vid.26. Panel O. View supplementary video at http://dx.doi. org/10.12945/j.jshd.2016.013.14.vid.27. Panel P. View supplementary video at http://dx.doi.org/10.12945/j.jshd.2016.013.14.vid.28. 
to place a 12-mm Amplatzer Vascular Plug ${ }^{\circledR}$ in the middle portion of the fistula, as we calculated the distal fistula to be approximately $10 \mathrm{~mm}$ in diameter. The CS had multiple loops, resulting in poor torque control and an inability to precisely withdraw the catheter slowly. The device slipped back into the CS (Figure 4M). We then changed our strategy to a retrograde approach, due to the difficulty we encountered with the previous attempt. We once again made an AV loop, as demonstrated above and passed an 8 Fr. AGA ${ }^{\circledR}$ delivery system up to the mid LCx over the stiff exchange length Glidewire ${ }^{\circledR}$ to deliver an $18-\mathrm{mm}$ Amplatzer Vascular Plug ${ }^{\circledR}{ }^{\circledast}$ to successfully close the fistula (Figure $4 \mathrm{~N} \& \mathrm{P}$ ). As there was a branch originating beyond the site of occlusion, we left the device attached for about 15 minutes and released it only when patient remained asymptomatic and there were no changes on electrocardiogram.

This case highlights the complexities involved in closing large and tortuous CAFs, even through venous side. Often, 0.035 -inch wires are used to make an AV loop to offer increased support for larger delivery sheaths. Waiting for a while before releasing the device, to assess for evidence of myocardial ischemia was important. The device could have been retrieved, if the patient had any chest pain or the ECG demonstrated ischemic changes.

\section{Retrograde Approach with an AV Loop}

Here we demonstrate a large distal fistula from the RCA to the CS. Diagnostic angiography was performed using a 6 Fr. AL2 ${ }^{\circledR}$ guide (Figure $5 \mathrm{~A}$ ). An initial attempt of using $5 \mathrm{Fr}$. balloon wedge catheter over a wire into the distal RCA failed (Figure 5B), so we used an $8 \mathrm{Fr}$. AL2 ${ }^{\circledR}$ guide and $5 \mathrm{Fr}$. multipurpose catheter in a 'mother-child' format into the distal RCA. We used a 0.035 -inch exchange length Glidewire ${ }^{\circledR}$ via the multipurpose catheter to exit the CS into the RA (Figure 5C). From there, it was snared and exteriorized through the femoral vein. We failed to advance any guide catheter through venous side into the CS, even using a kissing catheter technique over an AV loop. Eventually we advanced a 6 Fr. coronary guide catheter over the AV loop into the distal RCA from the retrograde approach, using the kissing catheter technique with a 4 Fr. SlipCath ${ }^{\circledR}$ in the inferior vena cava extending into the CS. Once we

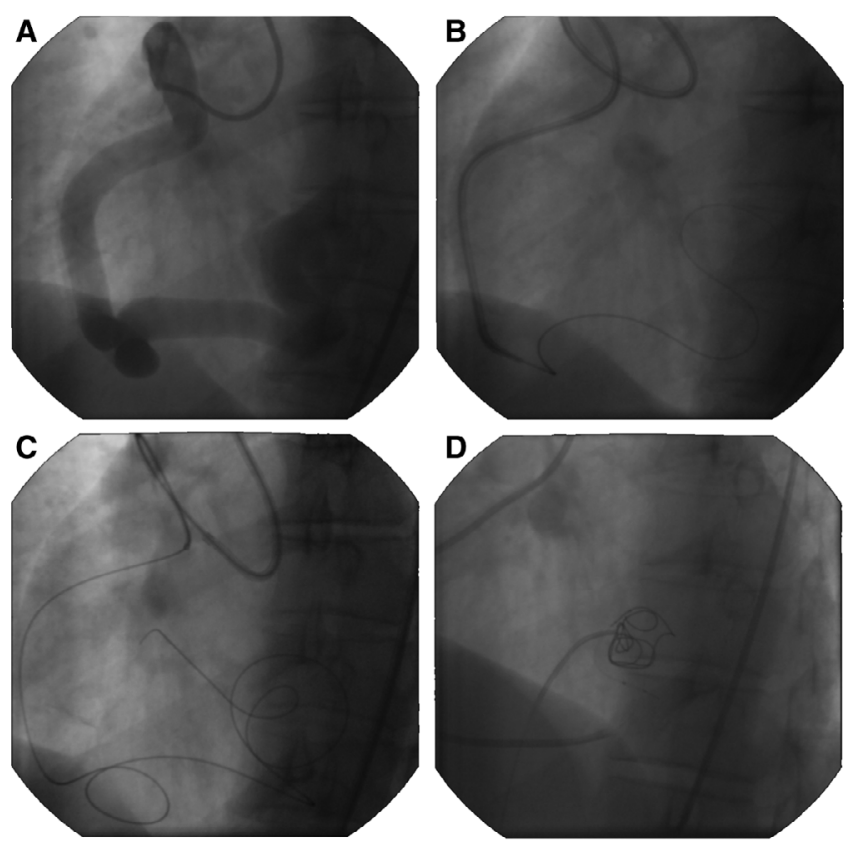

Figure 5. Retrograde approach - AV loop. Panel A. View supplementary video at http://dx.doi.org/10.12945/j.jshd.2016. 013.14.vid.29. Panel B. View supplementary video at http://dx.doi. org/10.12945/j.jshd.2016.013.14.vid.30. Panel C. View supplementary video at http://dx.doi.org/10.12945/j.jshd.2016.013.14. vid.31. Panel D. View supplementary video at http://dx.doi. org/10.12945/j.jshd.2016.013.14.vid.32.

were satisfied with the guide catheter position in the distal RCA, we used a $150-\mathrm{cm}$ Microferret ${ }^{\circledR}$ catheter $^{-}$ (Obex, Auckland, New Zealand) to deliver platinum embolization coils to successfully occlude the flow. The catheter was kept stabilized in the distal RCA with help of an AV loop (Figure 5D).

\section{Percutaneous Coronary Intervention Training}

TCC of CAFs is a challenging coronary intervention that can result in coronary complications. Having percutaneous coronary interventional expertise not only offers additional skills to perform the procedure, but also is advantageous in managing complications. Anomalous coronary origins are not uncommon, and sometimes finding a catheter that offers adequate engagement and support is a challenge. The case below demonstrates the importance of a broad range of interventional cardiology skills training. 


\section{Case}

A 55-year-old female presented with worsening exertional dyspnea. She was found to have two separate CAFs originating from proximal part of the RCA that had an anomalous origin and intra-arterial course. It was very difficult to obtain adequate catheter engagement, necessary for the procedure. We started with what we thought was going to be the best guide, an $A L 2^{\circledR}$; however, this sat poorly on the aortic valve and kept prolapsing (Figure 6A). We tried a number of different guides; eventually, a $\mathrm{LL}^{\circledR} 3.0$ guide engaged in the RCA ostium, although the support it offered remained poor (Figure 6B). The catheter prolapsed at the time of attempted coiling (Figure 6C). Using coils that can be retracted in such circumstances is very helpful. So, we placed a Prowater ${ }^{\circledast}$ coronary guide wire into the distal RCA, as an anchor wire to stabilize the catheter position (Figure 6D). This oriented the guide better and allowed us to use a Renegade ${ }^{\circledR}$ micro-catheter (Boston Scientific Inc., USA) over a Pilot ${ }^{\circledR} 50$ wire (Abbott Vascular Inc., USA) to enter the distal fistula. We deployed four platinum
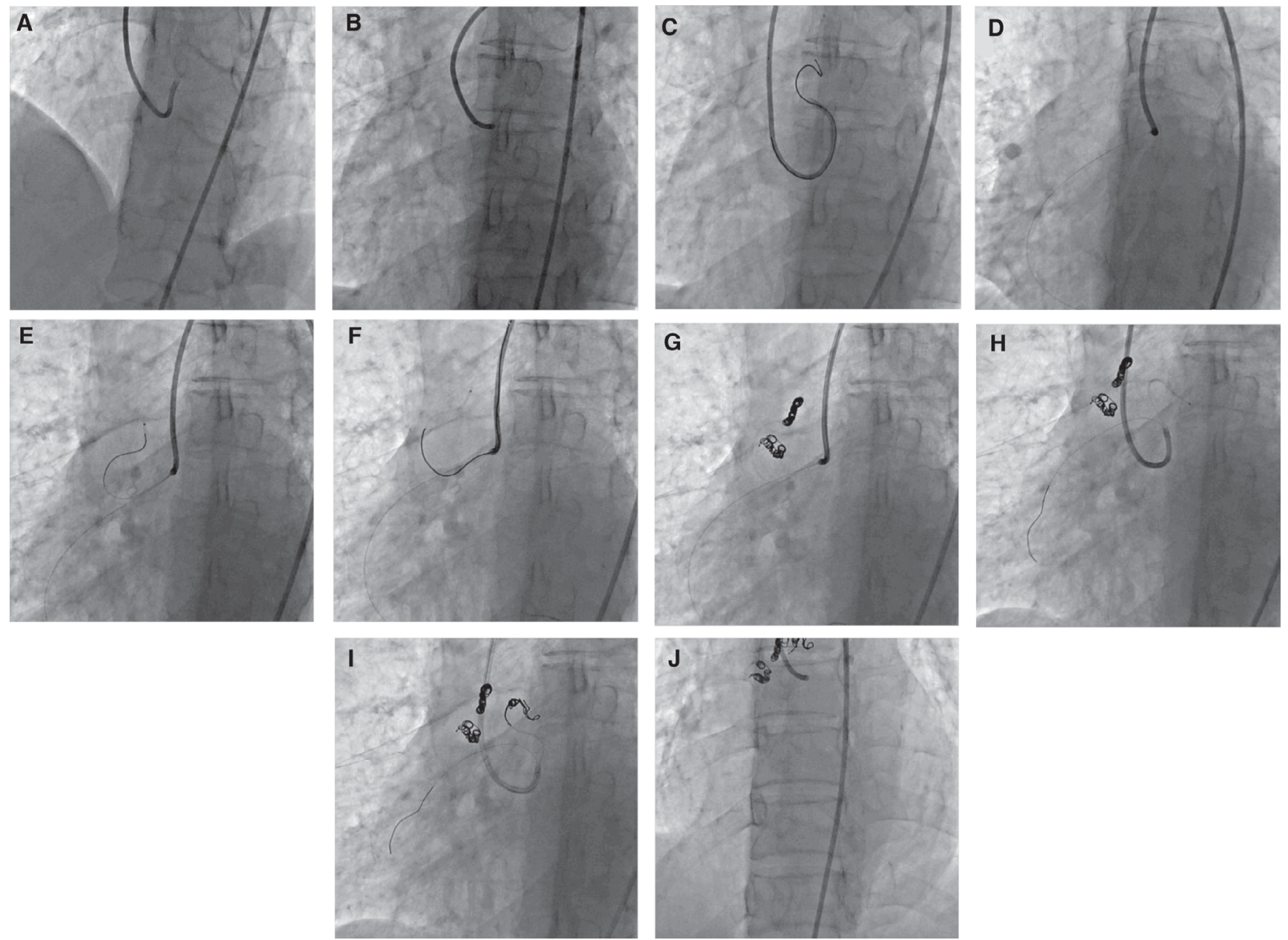

Figure 6. Important to have percutaneous coronary intervention skills. Panel A. View supplementary video at http://dx.doi.org/10.12945/j. jshd.2016.013.14.vid.33. Panel B. View supplementary video at http://dx.doi.org/10.12945/j.jshd.2016.013.14.vid.34. Pane/ C. View supplementary video athttp://dx.doi.org/10.12945/j.jshd.2016.013.14.vid.35.PanelD.View supplementary video athttp://dx.doi.org/10.12945/j.jshd.2016.013.14. vid.36 Panel E. View supplementary video at http://dx.doi.org/10.12945/j.jshd.2016.013.14.vid.37. Panel F. View supplementary video at http:// dx.doi.org/10.12945/j.jshd.2016.013.14.vid.38. Panel G. View supplementary video at http://dx.doi.org/10.12945/j.jshd.2016.013.14.vid.39. Panel H. View supplementary video at http://dx.doi.org/10.12945/j.jshd.2016.013.14.vid.40. Panel I. View supplementary video at http://dx.doi. org/10.12945/j.jshd.2016.013.14.vid.41. Panel J. View supplementary video at http://dx.doi.org/10.12945/j.jshd.2016.013.14.vid.42. 
interlock detachable IDC ${ }^{\circledast}$ coils measuring $3 \mathrm{~mm} \times 10 \mathrm{~cm}$ to successfully close the CAF (Figure $6 \mathrm{E} \& \mathrm{G}$ ). We then repositioned the guide allowing it to point upwards so we could wire the very proximal fistula. We were able to get the micro-catheter just proximal to the origin of the aneurysmal segment and deployed further IDC ${ }^{\circledast}$ coils, to successfully occlude all the fistulas (Figure $6 \mathrm{H}-J)$. The anchor wire helped us stabilize the guiding catheter position to achieve the final result.

\section{Multiple Coronary Artery Fistulas}

The majority of CAFs have a single feeding vessel but multiple feeding vessels are not rare (Figure 7A). Defining fistula branches and noting where they come off the coronary circulation is very important to understand before embarking on closure. As demonstrated in this case, it is important to systemically target as many feeding branches as possible to allow for vessel occlusion (Figure 7E \& F).

\section{Complications}

TCC of CAF is the treatment of choice today, with success rates at par with surgically performed procedures, but with lower morbidity and mortality $[1,18]$. Commonly encountered complications during TCC are as below,

\section{Branch Occlusion}

It is critical to adequately visualize distal branches which may be occluded or at risk of occlusion during the procedure. If a significant branch is at risk of occlusion, one should carefully consider the risk and benefits of the procedure.

\section{ECG Changes and Arrhythmias}

Careful monitoring of the 12 lead ECG during test occlusion and device deployment is critical to maintain safety. Our normal practice is to observe patients for the first 48 hours after fistula closure in a closely monitored environment, prior to considering for step-down. We do not anti-coagulate proximal fistulae, but routinely use heparin intra-operatively and warfarin after closure for large distal fistulae, where stasis may occur after successful occlusion.

\section{Device Embolization}

Coils and devices used to close CAF may dislodge and embolize at the time of deployment in a large fistula, due to high velocity flow. In a majority of reported cases coils could be retrieved, and no immediate complication were reported $[19,20]$.
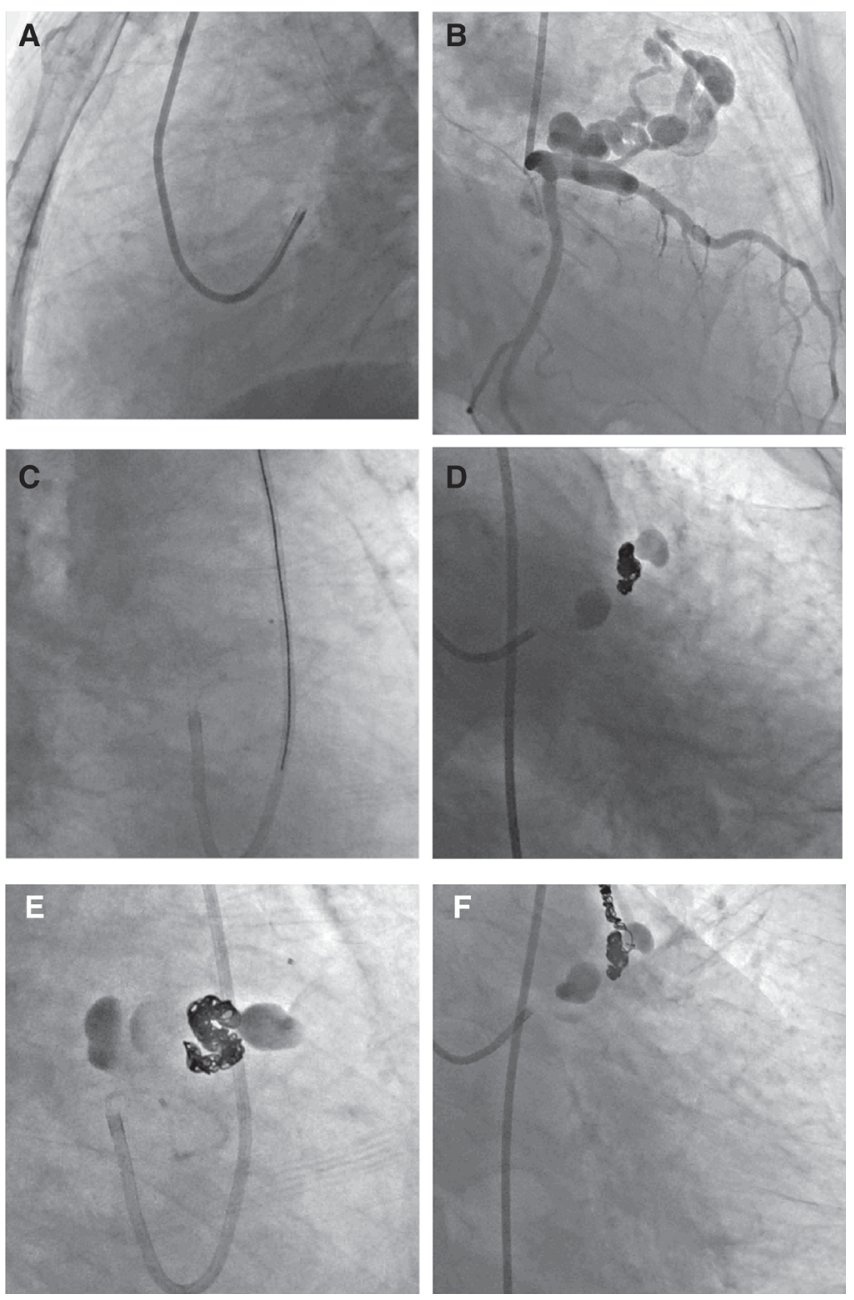

Figure 7. Multiple CAF. Panel A. View supplementary video at http://dx.doi.org/10.12945/j.jshd.2016.013.14.vid.43. Panel B. View supplementary video at http://dx.doi.org/10.12945/ j.jshd.2016.013.14.vid.44. Panel C. View supplementary video at http://dx.doi.org/10.12945/j.jshd.2016.013.14.vid.45. Panel D. View supplementary video at http://dx.doi.org/10.12945/ j.jshd.2016.013.14.vid.46. Panel E. View supplementary video at http://dx.doi.org/10.12945/j.jshd.2016.013.14.vid.47. Panel F. View supplementary video at http://dx.doi.org/10.12945/j.jshd.2016. 013.14.vid.48 


\section{Fistula Thrombosis}

Complete closure of large CAFs results in a culde-sac within the vasculature with stagnant blood flow and poor native vessel runoff, creating an environment for thrombus formation. In a series of 16 patients, distal type, large-sized fistula and old age at the time of presentation were considered high risk factors leading to coronary thrombosis after CAF closure [21].

\section{Thrombus Embolization}

Thrombus formation proximal to the device is not uncommon. In some cases, thrombus can propagate proximally and embolize into adjacent coronary vasculature, resulting in ischemic complications. We believe this is more likely to happen, if coils or devices are deployed into the very proximal part of the CAF. It is important to deploy the implants far from branches of coronary arteries to prevent thrombus embolization. Our preferred strategy is to deliver device through an antegrade approach.

\section{Myocardial Ischemia and Infarction}

Myocardial damage at the time of a TCC is often multifactorial. Compromise of flow in branches of the coronaries beyond the point of occlusion is the most common cause. Thrombus formation proximal to the occlusion point can propagate or embolize into proximal branches. Device, catheter, and wire passage at the time of the procedure can damage coronary vasculature [20]. One should keep close watch for such potential complications, especially when tortuosity requires aggressive techniques. Sequential troponin measurement and transthoracic echocardiograms after CAF closure can be valuable to assess possible myocardial damage. There should be a very low threshold for performing repeat coronary angiography, if there are any concerns with myocardial ischemia.

\section{Long-Term Follow Up and Unanswered Questions}

Follow up after successful surgical or percutaneous closure of the CAF has been reported in a few case series with small numbers. In most series, patients have been followed only clinically and they have been found to be asymptomatic. Residual leaks, thrombosis of the CAF, myocardial ischemia/myocardial infarction, persistent coronary dilatation, and death have been reported after initially successful percutaneous CAF closure [18, 21-23].

Angiographic follow up at 1.5 years in a group of patients who have undergone TCC demonstrated $44 \%$ of the patients had recanalization of the fistulae and half underwent re-intervention to achieve complete TCC, suggesting angiographic follow-up may be necessary in this cohort [24]. There is very limited long-term angiographic and clinical follow up data in the literature. It is not clear whether CAF closure results in prognostic benefit to the majority of these patients.

\section{Take Home Message}

- Adults are more symptomatic than children with CAF.

- Adults are more prone to rupture and atherosclerotic disease.

- Large CAF and symptomatic patients should be considered for closure procedure.

- Small CAF and those with atypical symptoms should not be considered for closure.

- CAF closure is not a routinely performed procedure.

- Surgical consultation should always be obtained.

- It is rare to find a significant Qp:Qs with CAF.

- Fully anticoagulate patients to avoid thrombotic complications.

- Plan a 'tailor-made' strategy for each individual case.

- Make sure to have various devices on the shelf.

- Necessary to have angioplasty skills readily available (yourself or a colleague).

- Be gentle with devices to avoid coronary complications.

- Careful evaluation for any potential complication before closing the case.

- Low threshold for repeat angiography if there is recurrence of symptoms, ECG changes, or new onset regional wall motion abnormality. 
- Limited evidence is available on long-term outcome and prognostic benefit of the closure procedure.

\section{Conflict of Interest}

The authors have no conflict of interest relevant to this publication.

\section{Comment on this Article or Ask a Question}

\section{References}

1. Liberthson RR, Sagar K, Berkoben JP, Weintraub RM, Levine FH. Congenital coronary arteriovenous fistula. Report of 13 patients, review of the literature and delineation of management. Circulation. 1979;59: 849-854. DOI: 10.1161/01.CIR.59.5.849

2. Latson LA. Coronary artery fistulas: how to manage them. Catheter Cardiovasc Interv. 2007;70:110-6. DOI: 10.1002/ccd.21125

3. Said SA, Lam J, van der Werf T. Solitary coronary artery fistulas: A congenital anomaly in children and adults. A contemporary review. Congen Heart Dis. 2006;1:63-76. DOI: 10.1111/j.1747-0803.2006.00012.x

4. Nawa S, Miyachi $Y$, Shiba $T$, et al. Clinical and angiographic analysis of congenital coronary artery fistulae in adulthood. Is there any new trend? Jap Heart J. 1996;37: 95-104. DOI: 10.1536/ihj.37.95

5. Yamanaka O, Hobbs RE. Coronary artery anomalies in 126, 595 patients undergoing coronary arteriography. Catheter Cardiovasc Diagn. 1990;21:28-40. DOI: 10.1002/ ccd.1810210110

6. Sherwood MC, Rockenmacher S, Colan SD. Prognostic significance of clinically silent coronary artery fistulas. Am J Cardiol. 1999;83:407-411. DOI: 10.1016/S00029149(98)00878-9

7. McNamara JJ, Gross RE. Congenital coronary artery fistula. Surgery. 1969;65: 59-69. PMID: 5762418

8. Holzer R, Johnson R, Ciotti G, Pozzi $M$, Kitchiner $D$. Review of an institutional experience of coronary arterial fistulas in childhood set in context of review of the literature. Cardiology Young. 2004;14:380-385. DOI: 10.1017/ S1047951104004056

9. Levin DC, Fellows KE, Abrams HL. Hemodynamically significant primary anomalies of the coronary arteries. Angiographic aspects. Circulation. 1978;58:25-34. DOI: 10.1161/01.CIR.58.1.25

10. Sakakibara S, Yokoyama M, Takao A, Nogi $\mathrm{M}$, Gomi H. Coronary arteriovenous fistula. Nine operated cases. Am Heart J. 1966;72:307-314. DOI: 10.1016/S0002$8703(66) 80004-2$
11. Reitz BA, Harrison LH, Jr., Michaelis LL. Experimental coronary artery fistula. J Thorac Cadiovasc Surg. 1975;69:278-282. PMID: 234556

12. Hori T, Matsubara T, Nakagawa I, et al. Prominent systolic coronary flow in a coronary artery fistula with a giant aneurysma. Jap Heart J. 2001;42:525-531. DOI: 10.1536/jhj.42.525

13. Warnes CA, Williams RG, Bashore TM, et al. ACC/AHA 2008 guidelines for the management of adults with congenital heart disease: A report of the American College of Cardiology/American Heart Association Task Force on Practice Guidelines (Writing Committee to Develop Guidelines on the Management of Adults With Congenital Heart Disease). Developed in Collaboration With the American Society of Echocardiography, Heart Rhythm Society, International Society for Adult Congenital Heart Disease, Society for Cardiovascular Angiography and Interventions, and Society of Thoracic Surgeons. J Am Coll Cardiol. 2008;52: e143-263. DOI: 10.1016/j.jacc.2008.10.001

14. Schleich JM, Rey C, Gewillig M, Bozio A. Spontaneous closure of congenital coronary artery fistulas. Heart. 2001;85:E6. DOI: 10.1136/heart.85.4.e6

15. Davis C, Jr., Dillon RF, Fell EH, Gasul BM. Anomalous coronary artery simulating patent ductus arteriosus. JAMA. 1956;160:1047-1050. DOI: 10.1001/jama.1956.02960470043010b

16. Fell EH, Weinberg M, Jr., Gordon AS, Gasul $B M$, Johnson FR. Surgery for congenital coronary artery arteriovenous fistulae. AMA Arch Surg. 1958;77:331-335. DOI: 10.1001/archsurg.1958.01290030031004

17. Reidy JF, Sowton E, Ross DN. Transcatheter occlusion of coronary to bronchial anastomosis by detachable balloon combined with coronary angioplasty at same procedure. Brit Heart J. 1983;49: 284-287. DOI: 10.1136/hrt.49.3.284

18. Armsby LR, Keane JF, Sherwood MC, Forbess JM, Perry SB, Lock JE. Management of coronary artery fistulae. Patient selection and results of tran- scatheter closure. J Am Coll Cardiol. 2002;39:1026-1032. DOI: 10.1016/S07351097(02)01742-4

19. Pedra CA, Pihkala J, Nykanen DG, Benson LN. Antegrade transcatheter closure of coronary artery fistulae using vascular occlusion devices. Heart. 2000;83:94-96. DOI: 10.1136/heart.83.1.94

20. Collins N, Mehta R, Benson L, Horlick E. Percutaneous coronary artery fistula closure in adults: technical and procedural aspects. Catheter Cardiovasc Interv. 2007;69:872-880. DOI: 10.1002/ccd.21085

21. Gowda ST, Latson LA, Kutty S, Prieto LR. Intermediate to long-term outcome following congenital coronary artery fistulae closure with focus on thrombus formation. Am J Cardiol. 2011;107:302-308. DOI: 10.1016/j.amjcard.2010.09.018

22. Kharouf R, Cao QL, Hijazi ZM. Transcatheter closure of coronary artery fistula complicated by myocardial infarction. J Invas Cardiol. 2007;19:E146-149. PMID: 17470976

23. Valente AM, Lock JE, Gauvreau K et al. Predictors of long-term adverse outcomes in patients with congenital coronary artery fistulae. Circulation Cardiovasc Interv. 2010;3:134-139. DOI: 10.1161/CIRCINTERVENTIONS.109.883884

24. Jama A, Barsoum M, Bjarnason $H$, Holmes DR, Jr., Rihal CS. Percutaneous closure of congenital coronary artery fistulae: Results and angiographic follow-up. JACC Cardiovasc Interv. 2011;4:814-821. DOI: 10.1016/j.jcin.2011.03.014

Cite this article as: Shah $\mathrm{AH}$, Leventhal A, Osten M, Benson L, Horlick E. Coronary Artery Fistulae: Indications For Treatment and Technical Considerations. Structural Heart Disease 2016;2(2): 47-57. DOI: http://dx.doi.org/10.12945/j. jshd.2016.013.14 